\title{
Clinical Significance of Neoadjuvant Chemotherapy With Gemcitabine Plus S-1 for Resectable Pancreatic Ductal Adenocarcinoma
}

\author{
TAKASHI SUZUKI, SHOZO MORI, TAKAYUKI SHIMIZU, KAZUMA TAGO, \\ NOBUHIRO HARADA, KYUNG-HWA PARK, YUHKI SAKURAOKA, \\ TAKAYUKI SHIRAKI, YUKIHIRO ISO, TAKU AOKI and KEIICHI KUBOTA
}

Department of Gastroenterological Surgery, Dokkyo Medical University, Tochigi, Japan

\begin{abstract}
Background/Aim: Little is known about the efficacy of neoadjuvant chemotherapy (NAC) with gemcitabine plus $S$ 1 (GS) for patients with resectable pancreatic ductal adenocarcinoma (R-PDAC). The aim of this study was to investigate differences in the long-term outcome of patients with $R$-PDAC undergoing pancreatectomy with and without $N A C-G S$ to clarify the clinical significance of NAC-GS. Patients and Methods: A total of 77 patients with R-PDAC who were scheduled for pancreatectomy between January 2012 and December 2017 were enrolled. Of these patients, 39 received NAC-GS (GS group) and 38 had upfront surgery (UFS group). Results: Among the 77 patients, one patient in each group did not undergo pancreatectomy due to intraoperative non-curative factors. Median tumor size and the number of lymph nodes with metastasis were significantly lower in the GS group than in the UFS group ( $p=0.002$ and $p=0.017)$. However, the 5-year overall survival rate was similar in the two groups $(26.1 \%$ versus $21.5 \%, p=0.930)$. Conclusion: NAC-GS may not be recommended for patients with $R-P D A C$ since it does not seem to offer any survival benefits.
\end{abstract}

Pancreatic ductal adenocarcinoma (PDAC) is an almost invariably fatal abdominal neoplasm with a 5-year overall survival (OS) rate of only 9\% (1). Although only surgical resection can offer curative treatment for patients with PDAC, the 5-year survival rate following surgery is extremely poor,

This article is freely accessible online.

Correspondence to: Keiichi Kubota, Department of Gastroenterological Surgery, Dokkyo Medical University, 880 Kitakobayashi, Mibu, Shimotsuga, Tochigi, 321-0293, Japan. Tel: +81 282872158, Fax: +81 282866317, e-mail: kubotak@dokkyomed.ac.jp

Key Words: Pancreatic cancer, neoadjuvant chemotherapy, adjuvant chemotherapy, gemcitabine, S-1. ranging from $6 \%$ to $30 \%(2-4)$, due to a high rate of cancer recurrence. In addition, surgical resection can be offered to only $15-20 \%$ of patients with PDAC at initial diagnosis (5, 6 ), because of the presence of distant metastases or tumor invasion to peripheral vessels including the common hepatic artery (CHA), superior mesenteric artery (SMA), and portal vein (PV). Therefore, improvement of resectability is mandatory for increasing the chance of cure.

A classification of PDAC resectability was introduced by the National Comprehensive Cancer Network (NCCN) guidelines, and is since being used worldwide (7). PDAC has been classified into three categories: i) resectable $(\mathrm{R})$, ii) borderline resectable (BR), or iii) unresectable (UR), based on residual tumor status evaluated by contrast-enhanced multidetector-row computed tomography (MDCT). Although a better $\mathrm{R} 0$ resection rate can be achieved in patients with $\mathrm{R}$ PDAC compared to patients with BR- or UR-PDAC, the 5year OS remains unsatisfactory (8-10).

Gemcitabine and S-1 are known to be key drugs for improving the survival of patients with $\operatorname{PDAC}(11,12)$. Therapy using a combination of gemcitabine plus S-1 (GS) was employed as standard for patients with advanced PDAC in Japan until the clinical introduction of fluorouracil/leucovorin plus irinotecan plus oxaliplatin (FOLFIRINOX) or gemcitabine plus nab-paclitaxel (GN) therapy (13-15). A randomized phase III study of gemcitabine plus S-1, S-1 alone, or gemcitabine alone in patients with locally advanced and metastatic pancreatic cancer (GEST study) has been conducted in Japan and Taiwan $(13,16)$. Although the superiority of GS to gemcitabine was not proved in terms of OS, the objective response rate and the median tumor shrinkage ratio were higher in the GS group compared to the gemcitabine and S-1 groups (29.3\% versus $13.3 \%$ and $21.0 \%$, respectively, and $20.9 \%$ versus $7.0 \%$ and $7.9 \%$, respectively). The GS combination was advantageous in terms of tumor shrinkage, possibly allowing $\mathrm{BR}$ and UR cases to become resectable. These results indicate that GS may be a favorable regimen for neoadjuvant 


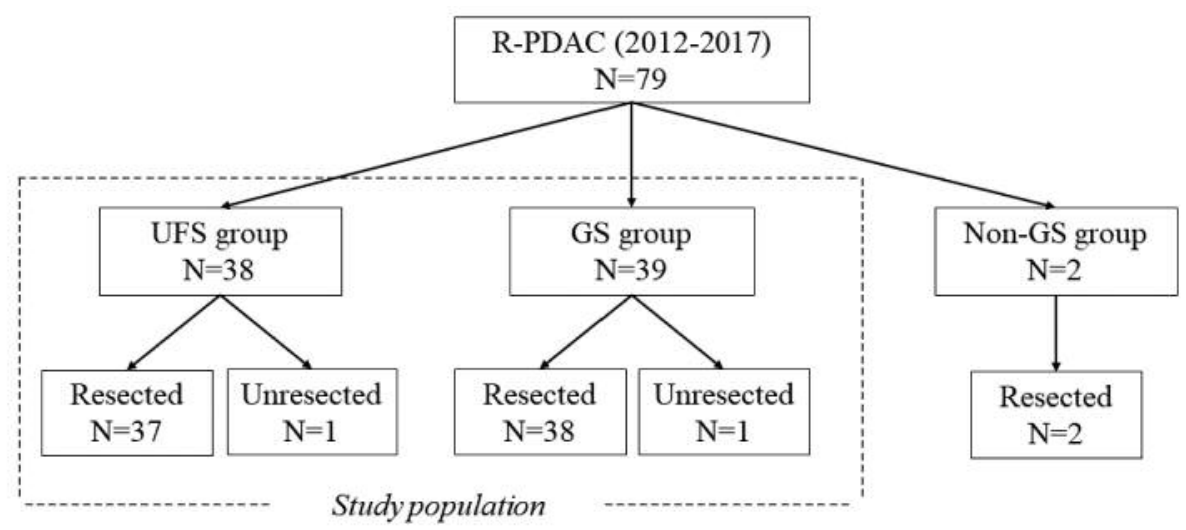

Figure 1. Flow chart of treatment course for patients with resectable pancreatic ductal adenocarcinoma (R-PDAC) from 2012 to 2017.

chemotherapy (NAC), and a clinical trial of NAC-GS for patients with R- and BR- PDAC has been conducted $(17,18)$. The results of this trial have suggested that, with sufficient tolerability and safety, NAC-GS may improve both survival and the R0 resection rate. However, the clinical significance of NAC-GS for patients with R-PDAC has remained unclear, as only a few studies have addressed this issue. Therefore, the aim of the present study was to investigate differences in the longterm outcome of patients with R-PDAC undergoing pancreatectomy with and without NAC-GS to clarify the clinical significance of NAC-GS.

\section{Patients and Methods}

A total of 131 patients with a clinical diagnosis of PDAC who were scheduled for elective surgery at the Department of Gastroenterological Surgery, Dokkyo Medical University Hospital, between January 2012 and December 2017 were retrospectively reviewed. Among these patients, those with R-PDAC without distant metastasis were included in this study. The diagnosis of RPDAC was based on the findings of contrast-enhanced MDCT, according to the NCCN guidelines version 2, 2018 (7). R-PDAC was defined as both absence of tumor contact with the celiac artery (CA), SMA, or CHA and absence of tumor contact with the superior mesenteric vein (SMV) or PV, or $\leq 180$ contact without vein contour irregularity. Distant metastasis was evaluated by MDCT and/or magnetic resonance imaging, and/or positron emission tomography. Among the patients with R-PDAC, those who underwent NAC followed by surgery were categorized as the GS group, and those who had undergone surgery without NAC as initial treatment were categorized as the upfront surgery (UFS) group. This study was approved by the ethics committee of Dokkyo Medical University (Ethical committee review number R-15-8J).

Pancreatoduodenectomy, distal pancreatectomy, or total pancreatectomy with regional lymph node dissection was performed, according to the tumor location. PV or SMV resection to achieve curative resection was undertaken if tumor invasion was recognized or suspected during surgery. When distant metastases to areas, such as the liver, extra-regional lymph nodes $(\mathrm{LN})$ or peritoneum, or tumor invasion to the CHA or CA were found during surgery, these were judged as inoperable cases. Postoperative complications were classified according to the Clavien-Dindo classification (19).

Pathological features of the resected specimens were classified according to the seventh edition of the Japanese Rules for Pancreatic Cancer and the eighth edition of the American Joint Committee on Cancer (AJCC) staging manual for pancreatic cancer $(20,21)$.

$\mathrm{LN}$ ratio was determined by dividing the number of LNs with metastasis by the total number of LNs dissected.

GS group. The dosage of gemcitabine and S-1 given to the patients who received NAC was based on the results of a phase II studies of GS therapy $(17,22)$. Gemcitabine was given at a dose of $1000 \mathrm{mg} / \mathrm{m}^{2}$ on days 1 and 8 of each course. S- 1 was provided orally at a dose of 40,50 , or $60 \mathrm{mg} / \mathrm{m}^{2}$ twice daily according to body surface area (less than $1.25 \mathrm{~m}^{2}, 1.25-1.5 \mathrm{~m}^{2}$, or over $1.5 \mathrm{~m}^{2}$ ) for the first 14 consecutive days followed by a 7-day rest. Each course was repeated every 21 days. Patients received two courses of GS therapy. The Common Terminology Criteria for Adverse Events (CTCAE) version 5.0 was used for the evaluation of treatment-related toxicities (23). Relative dose intensity (RDI) for gemcitabine and S-1 was calculated as the dose intensity achieved according to the standard schedule for each drug. Average RDI was calculated as the average of each RDI for gemcitabine and S-1. The Response Evaluation Criteria in Solid Tumors (RECIST) were utilized for evaluation of the response rate (24). The pathological response to the chemotherapy was categorized according to Evans' classification (25).

Statistical analysis. SPSS version 25.0 (IBM Japan, Tokyo, Japan) was used for all statistical analyses. Continuous data were expressed as medians with ranges and compared using the Mann-Whitney $U$ test, while categorical data were compared using the chi-squared test or Fisher's test. Survival curves were calculated using the Kaplan-Meier method and were compared using the log-rank test. Uni- and multivariate analyses were performed using the log-rank test, and the Cox proportional hazards forward stepwise model was used to identify risk factors for OS. Differences at $p<0.05$ were considered statistically significant. 
Suzuki et al: Neoadjuvant Chemotherapy for Pancreatic Ductal Adenocarcinoma

Table I. Preoperative clinical outcomes of patients with resectable pancreatic ductal adenocarcinoma who underwent surgery.

\begin{tabular}{lccc}
\hline Characteristics & $\begin{array}{c}\text { UFS group } \\
(\mathrm{n}=38)\end{array}$ & $\begin{array}{c}\text { GS group } \\
(\mathrm{n}=39)\end{array}$ & $p$-Value \\
\hline Age (years) & $67(46-82)$ & $65(43-80)$ & 0.359 \\
Gender (male/female) & $27 / 11$ & $23 / 16$ & 0.267 \\
Location (head/body-tail) & $26 / 12$ & $23 / 16$ & 0.389 \\
Tumor size (mm) & $25.4(10-66)$ & $23.1(10.2-42)^{*}$ & 0.273 \\
Biliary drainage $(+)$ & $21(55 \%)$ & $18(46 \%)$ & 0.424 \\
CEA (ng/ml) & $3.2(1-40.3)$ & $2.5(1-40.3)^{*}$ & 0.783 \\
CA19-9 (U/l) & $260.5(2-12000)$ & $159(2-2730)^{*}$ & 0.330 \\
Dupan-2 (U/ml) ${ }^{\dagger}$ & $81(25-3000)$ & $162(25-4000)^{*}$ & 0.518 \\
Span-1 (U/ml $)^{\ddagger}$ & $41(1-2170)$ & $38(1.3-270)^{*}$ & 0.315 \\
Elastase-1 (ng/d) & $334(50-3528)$ & $161(25-3910)^{*}$ & 0.332 \\
\hline
\end{tabular}

Data are expressed as median (range). *Measurement before GS therapy. $†$ Missing data $(n=3)$. $¥$ Missing data $(n=3)$. JMissing data $(n=7)$. CA19-9: Carbohydrate antigen 19-9; CEA: carcinoembryonic antigen; Dupan-2: pancreatic cancer associated antigen; GS: gemcitabine plus S1; Span-1: S-pancreas-1; UFS: upfront surgery.

Table II. Surgical outcomes of patients with resectable pancreatic ductal adenocarcinoma who underwent pancreatectomy.

\begin{tabular}{lccc}
\hline Characteristics & $\begin{array}{c}\text { UFS group } \\
(\mathrm{n}=37)\end{array}$ & $\begin{array}{c}\text { GS group } \\
(\mathrm{n}=38)\end{array}$ & $p$-Value \\
\hline Type of surgery (PD/DP/TP) & $25 / 10 / 2$ & $22 / 16 / 0$ & 0.168 \\
Portal vein resection (+) & $4(11 \%)$ & $6(16 \%)$ & 0.385 \\
Operation time (min) & $453(254-661)$ & $479(208-685)$ & 0.660 \\
Blood loss (ml) & $599(50-1781)$ & $623(50-3579)$ & 0.282 \\
Complications & & & 0.525 \\
$\quad$ C-D grade 0-II/III-V) & $25 / 12$ & $23 / 15$ & 0.493 \\
In-hospital death & $1(2.7 \%)$ & 0 & 0.844 \\
Postoperative hospital & & & 0.226 \\
stay (days) & $28(11-49)$ & $25(11-153)$ & $35(92 \%)$ \\
Adjuvant chemotherapy (+) & $31(84 \%)$ & & \\
\hline
\end{tabular}

Data are expressed as median (range). C-D: Clavien-Dindo classification; DP: distal pancreatectomy; GS: gemcitabine plus S-1; PD: pancreatoduodenectomy; TP: total pancreatectomy; UFS: upfront surgery.

\section{Results}

Preoperative patient characteristics. Seventy-nine patients $(60.3 \%)$ with R-PDAC were treated during the same period (2012-2017). A flow chart of the treatment course for patients with R-PDAC is shown in Figure 1. Thirty-eight patients underwent surgery without NAC (UFS group) and 39 patients initially received the GS regimen (GS group). The remaining 2 patients who received other regimens, including GS 1 course followed by the GN 1 course were excluded from the study. In the UFS group, 37 (97.4\%)
Table III. Comparison of clinical data before and after GS therapy.

\begin{tabular}{lc}
\hline Variables & GS group $(\mathrm{n}=39)$ \\
\hline Reduction rate $(\%)$ & \\
CEA & $-15.4(-145.5-71.1)$ \\
CA19-9 & $39.9(-108.2-94)$ \\
Dupan-2 & $36.2(-41.7-84.9)$ \\
Span-1 & $40.7(-100-82.5)$ \\
Elastase-1 & $29.2(-220-98.6)$ \\
Tumor size & $19(-16-46.5)$ \\
Radiographic response (CR/PR/SD/PD) & $0 / 6 / 33 / 0$ \\
ARDI $(\%)$ & $90.8(39.3-100)$ \\
Body weight loss $(\mathrm{kg})$ & $1.9(-3-15.1)$ \\
\hline
\end{tabular}

Data are expressed as median (range). ARDI: Average relative dose intensity; CA19-9: carbohydrate antigen 19-9; CEA: carcinoembryonic antigen; CR: complete response; Dupan-2: pancreatic cancer-associated antigen; GS: gemcitabine plus S-1; NAC: neoadjuvant chemotherapy; PD: progressive disease; PR: partial response; SD: stable disease; Span1: S-pancreas-1.

patients underwent pancreatectomy and 1 patient did not because of liver metastasis. In the GS group, 38 patients (97.4\%) underwent pancreatectomy and 1 patient did not because of para-aortic LN metastasis.

Table I shows the preoperative clinical data for the UFS and GS groups. There were no significant inter-group differences in terms of age, gender, tumor location, tumor size, biliary drainage, and levels of serum tumor markers, such as carcinoembryonic antigen (CEA), carbohydrate antigen 19-9 (CA19-9), pancreatic cancer-associated antigen (Dupan-2), S-pancreas-1 (Span-1), and elastase-1.

Surgical outcomes. Surgical outcomes in the UFS and GS patients who underwent pancreatectomy are listed in Table II. There were no significant inter-group differences in the type of surgery, PV resection, operation time, blood loss, postoperative complications, in-hospital deaths, postoperative hospital stays, and adjuvant chemotherapy (AC). AC, such as gemcitabine $(n=12), S-1(n=52)$, and other $(n=2)$ had been used in 9, 20, and 2 UFS group patients and in 3,32 , and $0 \mathrm{GS}$ group patients, respectively.

Tumor response to NAC. Table III shows the changes in clinical parameters following GS therapy relative to those before the therapy. The degrees of reduction in the levels of tumor markers were $-15.4 \%(-145.5-71.1)$ for CEA, $39.9 \%$ (-108.2-94) for CA19-9, 36.2\% (-41.7-84.9) for Dupan-2, $40.7 \%(-100-82.5)$ for Span-1, and $29.2 \%$ (-220-98.6) for elastase-1. Four of the tumor markers, with the exception of CEA, decreased from the baseline following GS therapy. The degree of reduction in tumor size was $19 \%$ (-16-46.5). None of the patients showed a complete response (CR) or 
in vivo $33: 2027-2035$ (2019)

Table IV. Adverse events of gemcitabine plus S-1 therapy ( $n=39)$.

\begin{tabular}{|c|c|c|c|c|c|c|}
\hline \multirow[t]{2}{*}{ Adverse event } & \multicolumn{4}{|c|}{ Grade } & \multirow{2}{*}{$\begin{array}{l}\text { Total } \\
\text { n (\%) }\end{array}$} & \multirow{2}{*}{$\begin{array}{c}\text { Grade } \\
3 / 4, \mathrm{n}(\%)\end{array}$} \\
\hline & 1 & 2 & 3 & 4 & & \\
\hline \multicolumn{7}{|l|}{ Hematological } \\
\hline Neutropenia & 2 & 6 & 13 & 5 & $26(66.7)$ & $18(46.2)$ \\
\hline Thrombocytopenia & 10 & 6 & 2 & 3 & $21(53.8)$ & $5(12.8)$ \\
\hline Anemia & 10 & 8 & 3 & 0 & $21(53.8)$ & $3(7.7)$ \\
\hline Febrile neutropenia & 0 & 0 & 2 & 2 & $4(10.3)$ & $4(10.3)$ \\
\hline \multicolumn{7}{|l|}{ Non-hematological } \\
\hline Rash & 5 & 7 & 4 & 0 & $16(41)$ & $4(10.3)$ \\
\hline AST increase & 10 & 2 & 3 & 0 & $15(38.5)$ & $3(7.7)$ \\
\hline ALT increase & 11 & 1 & 3 & 0 & $15(38.5)$ & $3(7.7)$ \\
\hline Mucositis & 4 & 2 & 3 & 0 & $9(23.1)$ & $3(7.7)$ \\
\hline Anorexia & 3 & 0 & 1 & 0 & $4(10.3)$ & $1(2.6)$ \\
\hline Nausea & 3 & 1 & 0 & 0 & $4(10.3)$ & 0 \\
\hline Cholangitis & 0 & 0 & 3 & 0 & $3(7.7)$ & $3(7.7)$ \\
\hline Diarrhea & 1 & 0 & 1 & 0 & $2(5.1)$ & $1(2.6)$ \\
\hline Fever & 2 & 0 & 0 & 0 & $2(5.1)$ & 0 \\
\hline Creatinine increase & 2 & 0 & 0 & 0 & $2(5.1)$ & 0 \\
\hline Vomiting & 0 & 0 & 1 & 0 & $1(2.6)$ & $1(2.6)$ \\
\hline Sepsis & 0 & 0 & 1 & 0 & $1(2.6)$ & $1(2.6)$ \\
\hline Duodenal ulcer & 0 & 0 & 1 & 0 & $1(2.6)$ & $1(2.6)$ \\
\hline Constipation & 1 & 0 & 0 & 0 & $1(2.6)$ & 0 \\
\hline Eye pain & 1 & 0 & 0 & 0 & $1(2.6)$ & 0 \\
\hline Alopecia & 0 & 1 & 0 & 0 & $1(2.6)$ & 0 \\
\hline Dyspepsia & 0 & 1 & 0 & 0 & $1(2.6)$ & 0 \\
\hline Malaise & 1 & 0 & 0 & 0 & $1(2.6)$ & 0 \\
\hline
\end{tabular}

AST: Aspartate aminotransferase; ALT: alanine aminotransferase.

progressive disease (PD), 6 patients showed a partial response (PR), and 33 patients showed stable disease (SD). The median relative dose intensity (RDI) of gemcitabine and S-1 was $100 \%$ (40-100) and 100\% (28.6-100), respectively. The average RDI was 90.8\% (39.3-100). Patients lost $1.9 \mathrm{~kg}$ in body weight (-3-15.1) during the GS therapy.

The maximum tumor size measured by preoperative CT was well correlated with the resected specimen (Spearman correlation coefficient, $R^{2}=0.616, p=0.01$, data not shown).

Toxicity and adverse events. The GS-related toxicities are shown in Table IV. All of the 39 patients were assessable for adverse events. Among them, 14 (35.9\%) completed two planned courses of GS therapy without any dose reduction and $11(28.2 \%)$ completed the course with dose down. However, $14(35.9 \%)$ could not complete the two courses. Hematological toxicities, such as neutropenia, thrombocytopenia, and anemia were common, occurring in $66.7 \%, 53.8 \%$, and $53.8 \%$ of the patients, respectively. The most common non-hematological toxicities were rash and increased levels of aspartate aminotransferase and alanine aminotransferase $(41 \%, 38.5 \%$, and $38.5 \%$, respectively). The most common grade $3 / 4$ adverse event was neutropenia (46.2\%).
Table V. Pathological outcomes of patients with resectable pancreatic ductal adenocarcinoma who underwent pancreatectomy.

\begin{tabular}{lccc}
\hline Characteristics & $\begin{array}{c}\text { UFS group } \\
(\mathrm{n}=37)\end{array}$ & $\begin{array}{c}\text { GS group } \\
(\mathrm{n}=38)\end{array}$ & $p$-Value \\
\hline Tumor size (mm) & $25(15-90)$ & $22(15-50)$ & 0.002 \\
T (T1/T2/T3)* & $4 / 27 / 6$ & $12 / 24 / 2$ & 0.046 \\
LN metastasis (+) & $29(78 \%)$ & $18(47 \%)$ & 0.006 \\
Number of dissected LNs & $20(6-49)$ & $17(3-69)$ & 0.454 \\
Number of LNs & & & \\
$\quad$ with metastasis & $1(0-11)$ & $1(0-12)$ & 0.017 \\
LN ratio & $0.122(0-0.563)$ & $0.033(0-0.706)$ & 0.014 \\
Stage (Ia/Ib/IIa/IIb/III)* & $0 / 7 / 1 / 19 / 10$ & $9 / 12 / 0 / 12 / 6$ & 0.012 \\
Histology & & & \\
$\quad$ (wel/mod/por/other) & $10 / 23 / 1 / 3$ & $15 / 16 / 5 / 2$ & 0.164 \\
Lymphatic invasion $(+)$ & $33(89 \%)$ & $27(71 \%)$ & 0.050 \\
Venous invasion (+) & $35(95 \%)$ & $34(89 \%)$ & 0.414 \\
Neuronal invasion (+) & $29(78 \%)$ & $35(92 \%)$ & 0.093 \\
Portal vein invasion** $\left.{ }^{*}+\right)$ & $6(16 \%)$ & $2(5 \%)$ & 0.122 \\
Residual tumor (R1) & $6(16 \%)$ & $2(5 \%)$ & 0.122 \\
Pathological response ${ }^{\dagger}$ & & & \\
$\quad$ (I/IIa/IIb/III) & n.a. & $9 / 24 / 4 / 1$ & n.a. \\
\hline
\end{tabular}

Data are expressed as median (range). *AJCC 8th edition. 'Evans' classification. **Invasion to portal vein or superior mesenteric vein or splenic vein. GS: Gemcitabine plus S-1; LNs: lymph nodes; Mod: moderately; Por: poorly; SF: surgery first; Wel: well.

Pathological outcomes. Pathological outcomes in the SF and GS groups are summarized in Table $\mathrm{V}$. The maximum tumor size was significantly less in the GS group compared to the SF group $(p=0.002)$. The numbers of dissected LNs were similar in the two groups. However, the number of LNs with metastasis and the LN ratio were significantly lower in the GS group compared to the $\mathrm{SF}$ group $(p=0.017$ and $p=0.014)$. Lymphatic invasion occurred less commonly in the GS group compared to the SF group $(p=0.050)$. However, the degrees of differentiation, venous invasion, neural invasion, $\mathrm{PV}$ invasion, and residual tumor status were similar in the two groups. Histological response evaluation according to Evans' classification revealed grade I, IIa, IIb, and III in $9(23.7 \%), 24(63.2 \%), 4(10.5 \%)$, and 1 (2.6\%) of the 38 patients, respectively.

Overall survival and relapse-free survival. The median follow-up period was 24.2 months (0.6-84.2) for the 75 patients who underwent pancreatectomy. The 5-year OS and relapse-free survival (RFS) rates in the SF and GS groups were $21.5 \%$ and $12.8 \%$, and $26.1 \%$ and $8 \%$, respectively ( $p=0.930$ and $p=0.764$, respectively) (Figure $2 \mathrm{~A}$ and B). The median OS and RFS periods in the SF and GS groups were 24.3 months and 15.6 months, and 21.5 months and 12.7 months, respectively. Recurrence was observed in 30 patients (81.1\%) in the SF group and 27 patients $(71.1 \%)$ in the GS group $(p=0.309)$. 

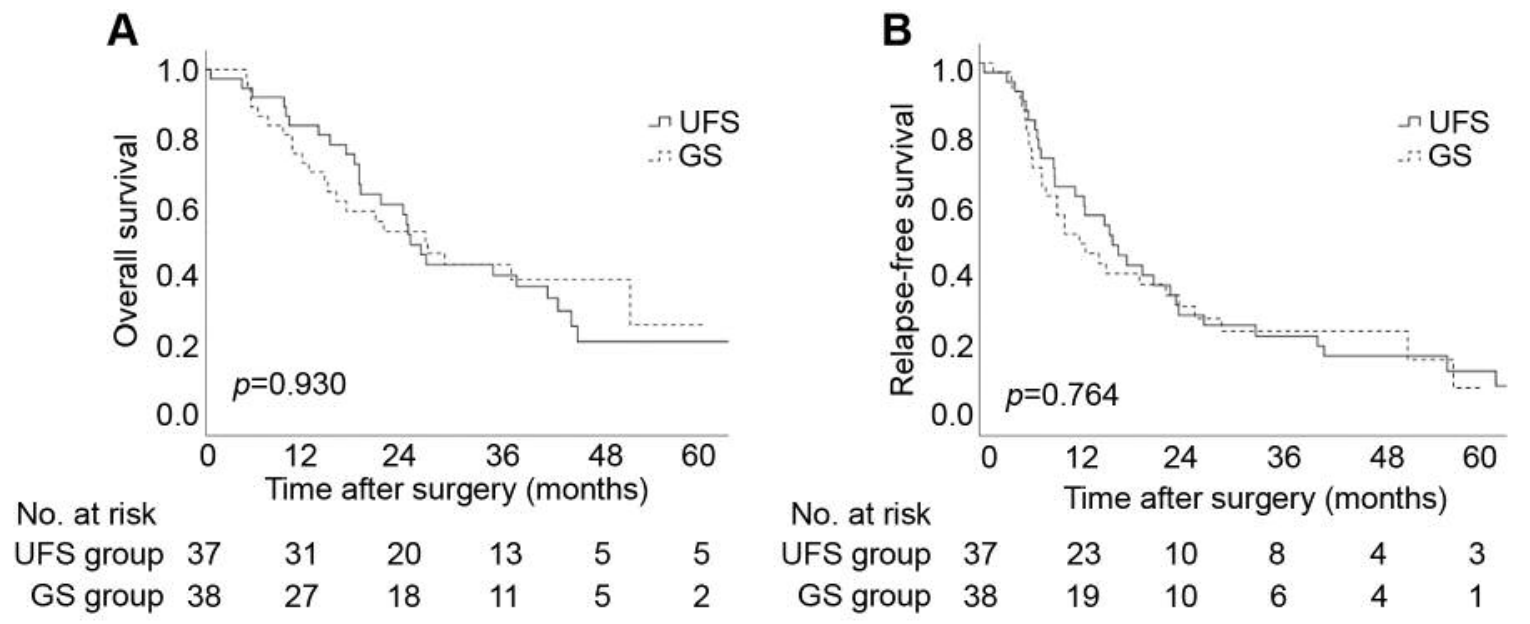

Figure 2. (A) Overall survival (OS) and (B) relapse-free survival (RFS) in the upfront surgery (UFS) (n=37) and gemcitabine plus $S$-1 (GS) ( $n=38)$ groups. There were no significant differences in OS and RFS between the two groups.

Table VI. Uni- and multivariate analyses of risk factors for survival ( $n=75)$.

\begin{tabular}{|c|c|c|c|c|c|}
\hline \multirow[b]{2}{*}{ Variables } & \multirow[b]{2}{*}{$\mathrm{n}$} & \multirow{2}{*}{$\frac{\text { Univariate }}{p \text {-Value* }}$} & \multicolumn{3}{|c|}{ Multivariate } \\
\hline & & & HR & $95 \% \mathrm{CI}$ & $p$-Value $* *$ \\
\hline Male & 49 & 0.685 & & & \\
\hline Age $\geq 75$ years & 15 & 0.048 & - & - & - \\
\hline $\mathrm{CEA}>5 \mathrm{ng} / \mathrm{ml}$ & 22 & 0.670 & & & \\
\hline CA19-9 >37 U/ml & 54 & 0.996 & & & \\
\hline Operation time $\geq 480 \mathrm{~min}$ & 28 & 0.982 & & & \\
\hline Blood loss $\geq 1000 \mathrm{ml}$ & 14 & 0.878 & & & \\
\hline Blood transfusion $(+)$ & 18 & 0.016 & - & - & - \\
\hline $\mathrm{T} 3,4$ & 8 & 0.002 & 2.900 & $1.308-6.428$ & 0.009 \\
\hline $\mathrm{LN}$ metastasis $(+)$ & 47 & 0.257 & & & \\
\hline $\mathrm{LN}$ ratio $>0.1$ & 31 & 0.009 & 2.040 & $1.147-3.628$ & 0.015 \\
\hline Histology (mod, por, or others) & 50 & 0.273 & & & \\
\hline Lymphatic invasion (+) & 60 & 0.134 & & & \\
\hline Venous invasion $(+)$ & 69 & 0.569 & & & \\
\hline Perineural invasion (+) & 64 & 0.624 & & & \\
\hline Portal vein invasion $(+)$ & 8 & 0.179 & & & \\
\hline Residual tumor (R1) & 8 & 0.224 & & & \\
\hline Adjuvant chemotherapy (-) & 9 & 0.002 & 3.569 & $1.636-7.783$ & 0.001 \\
\hline
\end{tabular}

*Log-rank test. **Cox proportional hazards model. CA19-9: Carbohydrate antigen 19-9; CEA: carcinoembryonic antigen; CI: confidence interval; HR: hazard ratio; LN: lymph node; Mod: moderately; Por: poorly.

Risk factors for survival. Table VI shows the results of uni- and multivariate analyses of risk factors for OS. Five of 17 factors were found to be significant by univariate analysis: i) age $>75$ years, ii) blood transfusion (+), iii) $\mathrm{T} 3,4$, iv) $\mathrm{LN}$ ratio $>0.1$, and v) AC (-). Multivariate analysis revealed that T3, 4 [hazard ratio $(\mathrm{HR})=2.900,95 \%$ Confidence Interval $(\mathrm{CI})=1.308-6.428$, $p=0.009), \mathrm{LN}$ ratio $>0.1 \quad(\mathrm{HR}=2.040,95 \% \mathrm{CI}=1.147-3.628$, $p=0.015)$, and $\mathrm{AC}(-)(\mathrm{HR}=3.569,95 \% \mathrm{CI}=1.636-7.783$, $p=0.001)$ were independent risk factor for poor OS.

\section{Discussion}

NAC offers several advantages over upfront surgery, including early delivery of anti-cancer drugs for control of micro-metastasis, high tolerability of multi-agent regimens, and a higher $\mathrm{R} 0$ resection rate, that may lead to a better prognosis. Various regimens including GS, GN, or FOLFIRINOX as NAC have been studied and reported to improve postoperative survival $(17,18,26-28)$. However, 
most of these studies were intended for patients with BR- or UR-PDAC, for whom an increase in the $\mathrm{R} 1$ resection rate was considered potentially feasible. The issue of whether the use of NAC is actually beneficial for patients with R-PDAC has remained unclear. Therefore, we prospectively investigated the clinical significance of NAC-GS only for patients with R-PDAC, classified on the basis of the NCCN guidelines, who were scheduled for surgery.

NAC has two potential risks. First, its toxicities may impact perioperative morbidity and mortality. In this study, the most common hematological and non-hematological toxicities were neutropenia $(66.7 \%)$ and rash $(41 \%)$, being grade $3 / 4$ in $46.2 \%$ and $10.3 \%$ of the patients, respectively. There was no NAC-GS-related mortality. All patients who suffered adverse events recovered and were scheduled for surgery. Comparable results have been reported previously in a phase II trial (17). No increase in operation time, blood loss, morbidity, or mortality was observed following NACGS treatment in our case, therefore, its use appears to be feasible and safe for patients with R-PDAC. Second, RPDAC may progress and become unresectable during the course of NAC. Motoi et al., have reported that $6(3.2 \%)$ of 185 patients with R-PDAC who received NAC with various regimens (mainly gemcitabine monotherapy) could not undergo surgery due to tumor progression (29). In the present study, however, R-PDAC did not become unresectable in any of the patients who received NAC-GS and planned surgery was performed as scheduled. Accordingly, NAC-GS may be useful for control of tumor progression in the short term.

NAC-GS decreased the levels of tumor markers such as CA19-9, Dupan-2, Span-1, and elastase-1, except for CEA. Because $28(71.8 \%)$ of 39 patients had a normal level of CEA before NAC-GS, only a slight change from the baseline level of CEA was observed following NACGS. Therefore, NAC-GS might not decrease the median level of CEA. Thirty-seven (94.9\%) of the 39 patients showed tumor shrinkage after NAC-GS, with a median reduction rate of $19 \%$. Although the number of dissected LNs was roughly equivalent between the UFS and GS groups, the number of LNs with metastasis and the LN ratio were significantly lower in the GS group compared to the UFS group. In 594 propensity score-matched patients with borderline resectable pancreatic cancer, Nagakawa et al., (30) have also demonstrated that neoadjuvant therapy is beneficial for reducing the number of LNs with metastasis. Thus, NAC could be expected to reduce the incidence of $\mathrm{LN}$ metastasis, as previous studies have already reported $(27,29)$. The proportion of patients with pathological stage I was significantly higher in the GS group compared to the UFS group, suggesting that the use of NAC-GS contributes to tumor down-staging in patients with R-PDAC.
In terms of long-term outcome, the 5-year OS and RFS rates did not differ significantly between the UFS and GS groups. It has been suggested that the CA19-9 response to NAC is associated with postoperative survival (31). However, the response of tumor markers, including CEA, CA19-9, Dupan2, Span-1 and elastase-1 to NAC had no impact on postoperative survival in the present study. Xia et al., (32) have reported that there is no correlation between the degree of radiologic response based on RECIST and the degree of pathological response according to Evans' classification in patients with BR-PDAC. Furthermore, in terms of pathological response, patients with Evans' grade IIb-IV showed improved OS relative to patients with Evans' grade I-IIa. The present study demonstrated a survival advantage for patients with Evans' grade IIa-III compared to patients with Evans' grade I. However, before the initiation of NAC-GS, it may be difficult to predict patients who would potentially benefit from it in terms of pathological response.

Two possible reasons why NAC-GS had no impact on postoperative survival in patients with R-PDAC can be suggested, despite the fact that NAC-GS contributed to tumor down-staging. First, there may have been some difference in residual tumor status between the UFS and GS groups. Among patients with BR-PDAC, Masui et al., (18) have reported that the frequency of $\mathrm{R} 0$ resection is significantly higher in those who receive NAC-GS than in those who do not $(87 \%$ versus $53 \%, p=0.002)$. It has been reported that the rate of R0 resection in upfront surgery for BR-PDAC patients ranges from $53 \%$ to $77 \%(18,26,29,30)$. The $\mathrm{R} 0$ resection rate is lower in patients with BR-PDAC compared to patients with R-PDAC due to the possible invasion of peripheral vessels and tissues. Conversely, the down-staging effects of NAC are more likely to improve the $\mathrm{R} 0$ resection rate, thus help prolong survival. However, in patients with R-PDAC, surgical resection without NAC can achieve a higher R0 resection rate, ranging from $81.3 \%$ to $90.2 \%(9,29,33)$. Therefore, it may be unlikely that NAC can further improve the $\mathrm{R} 0$ resection rate. In a systematic review and metaanalysis of prospective studies, Zhan et al., (33) have demonstrated that NAC has not been proven to be beneficial, and should be considered with caution in patients with $\mathrm{R}$ PDAC. In addition, AC may have a strong impact on postoperative survival. Surgical resection followed by AC, including gemcitabine or S-1, is the only treatment strategy currently available offering a chance of cure $(11,12,24)$. In the present study cohort, multivariate analysis revealed that the use of AC was the most powerful prognostic factor. While there were no significant differences between the UFS and GS groups in the number of patients who received AC and the period until initiation of AC after surgery. The use of NAC-GS did not affect the initiation of AC. Since Uesaka et al., (12) have demonstrated the superiority of S-1 to gemcitabine for patients undergoing PDAC resection in a 
phase III trial, $\mathrm{S}-1$ is often chosen for AC in Japan. In terms of postoperative survival, AC may be superior to NAC for patients with R-PDAC. Because parameters of surgical invasiveness, such as operation time, blood loss, and concomitant vascular resection are milder in patients with $\mathrm{R}$ PDAC compared to patients with BR- or UR-PDAC $(28,29)$, it may be more feasible to initiate $\mathrm{AC}$ without dose reduction.

Multivariate analysis in the present study showed that a $\mathrm{LN}$ ratio of $>0.1$ was associated with poor survival. Pawlik et al., (34) have demonstrated that a high $\mathrm{LN}$ ratio portends poor tumor biology and, as expected, poorer overall survival. Although NAC-GS was useful for reducing the LN ratio, patients who retain a high $\mathrm{LN}$ ratio might have tumors with a higher malignant potential.

Our study had several limitations that need to be pointed out. This was a single-center retrospective study that analyzed data for only a small number of patients with RPDAC during a 6-year period. Therefore, further prospective studies with larger numbers of patients will be required in order to reach definitive conclusions. At present, a randomized phase II/III trial of NAC with GS versus upfront surgery for resectable pancreatic cancer has begun, and the results of that study are awaited (35).

In conclusion, although the use of NAC-GS contributes to tumor down-staging, NAC-GS may not be recommended for the treatment of patients with R-PDAC because any survival benefits have yet to be demonstrated.

\section{Conflicts of Interest}

The authors have no conflicts of interest to declare.

\section{Authors' Contributions}

All Authors contributed to the design and implementation of the study, to the analysis of the results, and to the writing and final approval of the manuscript.

\section{References}

1 Siegel RL, Miller KD and Jemal A: Cancer statistics, 2019. CA Cancer J Clin 69(1): 7-34, 2019. PMID: 30620402. DOI: $10.3322 /$ caac. 21551

2 Nimura Y, Nagino M, Takao S, Takada T, Miyazaki K, Kawarada Y, Miyagawa S, Yamaguchi A, Ishiyama S, Takeda Y, Sakoda K, Kinoshita T, Yasui K, Shimada $\mathrm{H}$ and Katoh $\mathrm{H}$ : Standard versus extended lymphadenectomy in radical pancreatoduodenectomy for ductal adenocarcinoma of the head of the pancreas: long-term results of a Japanese multicenter randomized controlled trial. J Hepatobiliary Pancreat Sci 19(3): 230-241, 2012. PMID: 22038501. DOI: $10.1007 / \mathrm{s} 00534-011-0466-6$

3 Tomasello G, Ghidini M, Costanzo A, Ghidini A, Russo A, Barni S, Passalacqua R and Petrelli F: Outcome of head compared to body and tail pancreatic cancer: a systematic review and metaanalysis of 93 studies. J Gastrointest Oncol 10(2): 259-269, 2019. PMID: 31032093. DOI: 10.21037/jgo.2018.12.08
4 Egawa S, Toma H, Ohigashi H, Okusaka T, Nakao A, Hatori T, Maguchi H, Yanagisawa A and Tanaka M: Japan Pancreatic Cancer Registry; 30th year anniversary: Japan Pancreas Society. Pancreas 41(7): 985-992, 2012. PMID: 22750974. DOI: 10.1097/MPA.0b013e318258055c

5 Deplanque G and Demartines N: Pancreatic cancer: are more chemotherapy and surgery needed? Lancet 389(10073): 985-986, 2017. PMID: 28129986. DOI: 10.1016/S0140-6736(17)30126-5

6. Gillen S, Schuster T, Meyer Zum Büschenfelde C, Friess H and Kleeff J: Preoperative/neoadjuvant therapy in pancreatic cancer: a systematic review and meta-analysis of response and resection percentages. PLoS Med 7(4): e1000267, 2010. PMID: 20422030. DOI: 10.1371/journal.pmed.1000267

7 National Comprehensive Cancer Network: NCCN clinical practice guidelines in oncology (NCCN Guidelines). Pancreatic adenocarcinoma. Version 2. 2018. Available from: http:// www.neen.org/professionals/physician_gls/pdf/pancreatic.pdf

8 Motoi F, Unno M, Takahashi H, Okada T, Wada K, Sho M, Nagano H, Matsumoto I, Satoi S, Murakami Y, Kishiwada M, Honda G, Kinoshita H, Baba H, Hishinuma S, Kitago M, Tajima $\mathrm{H}$, Shinchi H, Takamori H, Kosuge T, Yamaue H and Takada T: Influence of preoperative anti-cancer therapy on resectability and perioperative outcomes in patients with pancreatic cancer: project study by the Japanese Society of Hepato-BiliaryPancreatic Surgery. J Hepatobiliary Pancreat Sci 21(2): 148-158, 2014. PMID: 23913634. DOI: 10.1002/jhbp.15

9 Nakamura T, Asano T, Okamura K, Tsuchikawa T, Murakami S, Kurashima Y, Ebihara Y, Noji T, Nakanishi Y, Tanaka K, Shichinohe $\mathrm{T}$ and Hirano $\mathrm{S}$ : A preoperative prognostic scoring system to predict prognosis for resectable pancreatic cancer: Who will benefit from upfront surgery? J Gastrointest Surg 23(5): 990-996, 2019. PMID: 30242645. DOI: 10.1007/s11605018-3972-x

10 Hong SB, Lee SS, Kim JH, Kim HJ, Byun JH, Hong SM, Song KB and Kim SC: Pancreatic Cancer CT: Prediction of resectability according to NCCN criteria. Radiology 289(3): 710-718, 2018. PMID: 30251929. DOI:10.1148/radiol.2018180628

11 Oettle H, Post S, Neuhaus P, Gellert K, Langrehr J, Ridwelski K, Schramm H, Fahlke J, Zuelke C, Burkart C, Gutberlet K, Kettner E, Schmalenberg H, Weigang-Koehler K, Bechstein WO, Niedergethmann M, Schmidt-Wolf I, Roll L, Doerken B and Riess H: Adjuvant chemotherapy with gemcitabine vs observation in patients undergoing curative-intent resection of pancreatic cancer: a randomized controlled trial. JAMA 297(3): 267-277, 2007. PMID: 17227978. DOI: 10.1001/jama.297.3.267

12 Uesaka K, Boku N, Fukutomi A, Okamura Y, Konishi M, Matsumoto I, Kaneoka Y, Shimizu Y, Nakamori S, Sakamoto H, Morinaga S, Kainuma O, Imai K, Sata N, Hishinuma S, Ojima H, Yamaguchi R, Hirano S, Sudo T, Ohashi Y and JASPAC 01 Study Group: Adjuvant chemotherapy of S-1 versus gemcitabine for resected pancreatic cancer: a phase 3, open-label, randomised, non-inferiority trial (JASPAC 01). Lancet 388(10041): 248-257, 2016. PMID: 27265347. DOI: 10.1016/S0140-6736(16)30583-9

13 Ueno H, Ioka T, Ikeda M, Ohkawa S, Yanagimoto H, Boku N, Fukutomi A, Sugimori K, Baba H, Yamao K, Shimamura T, Sho M, Kitano M, Cheng AL, Mizumoto K, Chen JS, Furuse J, Funakoshi A, Hatori T, Yamaguchi T, Egawa S, Sato A, Ohashi Y, Okusaka T and Tanaka M: Randomized phase III study of gemcitabine plus S-1, S-1 alone, or gemcitabine alone in patients with locally advanced and metastatic pancreatic cancer in Japan 
and Taiwan: GEST study. J Clin Oncol 31(13): 1640-1648, 2013 PMID: 23547081. DOI: 10.1200/JCO.2012.43.3680

14 Conroy T, Desseigne F, Ychou M, Bouché O, Guimbaud R, Bécouarn Y, Adenis A, Raoul JL, Gourgou-Bourgade S, de la Fouchardière C, Bennouna J, Bachet JB, Khemissa-Akouz F, Péré-Vergé D, Delbaldo C, Assenat E, Chauffert B, Michel P, Montoto-Grillot C, Ducreux M, Groupe Tumeurs Digestives of Unicancer and PRODIGE Intergroup: FOLFIRINOX versus gemcitabine for metastatic pancreatic cancer. N Engl J Med 364(19): 1817-1825, 2011. PMID: 21561347. DOI: 10.1056/ NEJMoa1011923

15 Von Hoff DD, Ervin T, Arena FP, Chiorean EG, Infante J, Moore M, Seay T, Tjulandin SA, Ma WW, Saleh MN, Harris M, Reni M, Dowden S, Laheru D, Bahary N, Ramanathan RK, Tabernero J, Hidalgo M, Goldstein D, Van Cutsem E, Wei X, Iglesias J and Renschler MF: Increased survival in pancreatic cancer with nabpaclitaxel plus gemcitabine. N Engl J Med 369(18): 1691-1703, 2013. PMID: 24131140. DOI: 10.1056/NEJMoa1304369

16 Okusaka T, Miyakawa H, Fujii H, Nakamori S, Satoh T, Hamamoto Y, Ito T, Maguchi H, Matsumoto S, Ueno H, Ioka T, Boku N, Egawa S, Hatori T, Furuse J, Mizumoto K, Ohkawa S, Yamaguchi T, Yamao K, Funakoshi A, Chen JS, Cheng AL, Sato A, Ohashi Y, Tanaka M and GEST group: Updated results from GEST study: a randomized, three-arm phase III study for advanced pancreatic cancer. J Cancer Res Clin Oncol 143(6): 1053-1059, 2017. PMID: 28210843, DOI: 10.1007/s00432-0172349-y

17 Motoi F, Ishida K, Fujishima F, Ottomo S, Oikawa M, Okada T, Shimamura H, Takemura S, Ono F, Akada M, Nakagawa K, Katayose Y, Egawa S and Unno M: Neoadjuvant chemotherapy with gemcitabine and S-1 for resectable and borderline pancreatic ductal adenocarcinoma: results from a prospective multiinstitutional phase 2 trial. Ann Surg Oncol 20(12): 3794-3801, 2013. PMID: 23838925. DOI: 10.1245/s10434-013-3129-9

18 Masui T, Doi R, Kawaguchi Y, Sato A, Nakano K, Ito T, Anazawa T, Takaori $\mathrm{K}$ and Uemoto $\mathrm{S}$ : Concurrent gemcitabine+S-1 neoadjuvant chemotherapy contributes to the improved survival of patients with small borderline-resectable pancreatic cancer tumors. Surg Today 46(11): 1282-1289, 2016. PMID: 26860274. DOI: 10.1007/s00595-016-1310-z

19 Clavien PA, Barkun J, de Oliveira ML, Vauthey JN, Dindo D, Schulick RD, de Santibañes E, Pekolj J, Slankamenac K, Bassi C, Graf R, Vonlanthen R, Padbury R, Cameron JL and Makuuchi $\mathrm{M}$ : The Clavien-Dindo classification of surgical complications: five-year experience. Ann Surg 250(2): 187-96, 2009. PMID: 19638912. DOI: 10.1097/SLA.0b013e3181b13ca2

20 Japanese Pancreas Society. General Rules for the Study of Pancreatic Cancer (7th edn) (in Japanese). Kanehara: Tokyo, 2016.

21 Amin MB, Edge S, Greene F, Byrd DR, Brookland RK, Washington MK, Gershenwald JE, Compton CC, Hess KR, Sullivan DC, Jessup JM, Brierley JD, Gaspar LE, Schilsky RL, Balch CM, Winchester DP, Asare EA, Madera M, Gress DM, Meyer LR: AJCC Cancer Staging Manual. 8th edn. Springer: New York, 2017.

22 Ueno H, Okusaka T, Furuse J, Yamao K, Funakoshi A, Boku N, Ohkawa S, Yokosuka O, Tanaka K, Moriyasu F, Nakamori S and Sato T: Multicenter phase II study of gemcitabine and S-1 combination therapy (GS Therapy) in patients with metastatic pancreatic cancer. Jpn J Clin Oncol 41(8): 953-958, 2011. PMID: 21715364. DOI: 10.1093/jjco/hyr090
23 Common Terminology Criteria for Adverse Events (CTCAE) v5.0. Available from: https://ctep.cancer.gov/protocoldevelopment/ electronic_applications/docs/CTCAE_v5_Quick_Reference_8.5x1 1.pdf

24 Therasse P, Arbuck SG, Eisenhauer EA, Wanders J, Kaplan RS, Rubinstein L, Verweij J, Van Glabbeke M, van Oosterom AT, Christian MC and Gwyther SG: New guidelines to evaluate the response to treatment in solid tumors. European Organization for Research and Treatment of Cancer, National Cancer Institute of the United States, National Cancer Institute of Canada. J Natl Cancer Inst 92(3): 205-216, 2000. PMID: 10655437. DOI: 10.1093/jnci/92.3.205

25 Evans DB, Rich TA, Byrd DR, Cleary KR, Connelly JH, Levin B, Charnsangavej C, Fenoglio CJ and Ames FC: Preoperative chemoradiation and pancreaticoduodenectomy for adenocarcinoma of the pancreas. Arch Surg 127(11): 1335-1339, 1992. PMID: 1359851. DOI: 10.1001/archsurg.1992.01420110083017

26 Miyasaka Y, Ohtsuka T, Kimura R, Matsuda R, Mori Y, Nakata K, Kakihara D, Fujimori N, Ohno T, Oda Y and Nakamura M: Neoadjuvant chemotherapy with gemcitabine plus nab-paclitaxel for borderline resectable pancreatic cancer potentially improves survival and facilitates surgery. Ann Surg Oncol 26(5): 1528-1534, 2019. PMID: 30868514. DOI: 10.1245/s10434-019-07309-8

27 Ferrone CR, Marchegiani G, Hong TS, Ryan DP, Deshpande V, McDonnell EI, Sabbatino F, Santos DD, Allen JN, Blaszkowsky LS, Clark JW, Faris JE, Goyal L, Kwak EL, Murphy JE, Ting DT, Wo JY, Zhu AX, Warshaw AL, Lillemoe KD and Fernández-del Castillo C: Radiological and surgical implications of neoadjuvant treatment with FOLFIRINOX for locally advanced and borderline resectable pancreatic cancer. Ann Surg 261(1): 12-17, 2015. PMID: 25599322. DOI: 10.1097/SLA.0000000000000867

28 Petrelli F, Coinu A, Borgonovo K, Cabiddu M, Ghilardi M, Lonati V, Aitini E, Barni S and Gruppo Italiano per lo Studio dei Carcinomi dell'Apparato Digerente (GISCAD): FOLFIRINOXbased neoadjuvant therapy in borderline resectable or unresectable pancreatic cancer: a meta-analytical review of published studies. Pancreas 44(4): 515-521, 2015. PMID: 25872127. DOI: 10.1097/MPA.0000000000000314

29 Motoi F, Unno M, Takahashi H, Okada T, Wada K, Sho M, Nagano H, Matsumoto I, Satoi S, Murakami Y, Kishiwada M, Honda G, Kinoshita H, Baba H, Hishinuma S, Kitago M, Tajima H, Shinchi H, Takamori H, Kosuge T, Yamaue H and Takada T: Influence of preoperative anti-cancer therapy on resectability and perioperative outcomes in patients with pancreatic cancer: project study by the Japanese Society of Hepato-BiliaryPancreatic Surgery. J Hepatobiliary Pancreat Sci 21(2): 148-158, 2014. PMID: 23913634. DOI: 10.1002/jhbp.15

30 Nagakawa Y, Sahara Y, Hosokawa Y, Murakami Y, Yamaue H, Satoi S, Unno M, Isaji S, Endo I, Sho M, Fujii T, Takishita C, Hijikata Y, Suzuki S, Kawachi S, Katsumata K, Ohta T, Nagakawa $\mathrm{T}$ and Tsuchida A: Clinical impact of neoadjuvant chemotherapy and chemoradiotherapy in borderline resectable pancreatic cancer: Analysis of 884 patients at facilities specializing in pancreatic surgery. Ann Surg Oncol 26(6): 1629-1636, 2019. PMID: 30610555. DOI: $10.1245 / \mathrm{s} 10434-018-07131-8$

31 Boone BA, Steve J, Zenati MS, Hogg ME, Singhi AD, Bartlett DL, Zureikat AH, Bahary N and Zeh HJ 3rd: Serum CA 19-9 response to neoadjuvant therapy is associated with outcome in pancreatic adenocarcinoma. Ann Surg Oncol 21(13): 4351-4358, 2014. PMID: 25092157. DOI: 10.1245/s10434-014-3842-z 
32 Xia BT, Fu B, Wang J, Kim Y, Ahmad SA, Dhar VK, Levinsky NC, Hanseman DJ, Habib DA, Wilson GC, Smith M, Olowokure OO, Kharofa J, Al Humaidi AH, Choe KA, Abbott DE and Ahmad SA: Does radiologic response correlate to pathologic response in patients undergoing neoadjuvant therapy for borderline resectable pancreatic malignancy? J Surg Oncol 115(4): 376-383, 2017. PMID: 2810563. DOI: 10.1002/jso.24538

33 Zhan HX, Xu JW, Wu D, Wu ZY, Wang L, Hu SY and Zhang GY: Neoadjuvant therapy in pancreatic cancer: a systematic review and meta-analysis of prospective studies. Cancer Med 6(6): 12011219, 2017. PMID: 28544758. DOI: 10.1002/cam4.1071

34 Pawlik TM, Gleisner AL, Cameron JL, Winter JM, Assumpcao L, Lillemoe KD, Wolfgang C, Hruban RH, Schulick RD, Yeo CJ and Choti MA: Prognostic relevance of lymph node ratio following pancreaticoduodenectomy for pancreatic cancer. Surgery 141(5): 610-618, 2007. PMID: 17462460. DOI: 10.1016/j.surg. 2006.12.013
35 Motoi F, Kosuge T, Ueno H, Yamaue H, Satoi S, Sho M, Honda G, Matsumoto I, Wada K, Furuse J, Matsuyama Y, Unno M, Study Group of Preoperative Therapy for Pancreatic Cancer (Prep) and Japanese Study Group of Adjuvant Therapy for Pancreatic cancer (JSAP): Randomized phase II/III trial of neoadjuvant chemotherapy with gemcitabine plus S-1 versus upfront surgery for resectable pancreatic cancer (Prep02/JSAP05). Jpn J Clin Oncol 49(2): 190-194, 2019. PMID: 30608598. DOI: $10.1093 /$ jjco/hyy 190
Received July 11, 2019

Revised August 5, 2019

Accepted August 8, 2019 